\title{
4. Sensing Screens: From Surface to Situation
}

\author{
Nanna Verhoeff
}

\begin{abstract}
Nanna Verhoeff considers recent screen-based public art installations that extend from their architectural site into surrounding urban space in order to engage techniques of 'remote sensing', interactivity, and public display. In these installations, Verhoeff identifies a genre of artwork that aims to raise awareness of urban social issues by visualizing and making 'present' otherwise invisible crises relating to the meeting of the social and the environmental. These installations compel one to look past the surface of the screen to its surrounding situation. Verhoeff thus reorients cinematic concepts of the dispositif towards a broader spectatorial territory, which she identifies by its building-scaled interfaces that reach beyond their location to remake, create, and influence the physical context by sensibly linking it to other, more distant spaces.
\end{abstract}

Keywords: Dispositif, Locative Media, Space, Urban Screen, Spectatorship, Aesthetics

\section{In the Air Tonight}

The recent public art installation In the Air Tonight uses light and architectural surface for data visualization. (Figures 4.1 and 4.2) The project, by Toronto-based artists Patricio Davilla and Dave Colangelo of Public Visualization Studios, makes use of a LED façade of the Ryerson Image Center in Toronto. It is a temporary but recurring installation for a pre-existing and fixed architecture. It was on display for one month in 2014, and again in 2015 and 2016, with the aim of raising awareness of homelessness in the city. Throughout the cold winter evenings, a blue wave on the façade

Buckley, C., R. Campe, F. Casetti (eds.), Screen Genealogies. From Optical Device to Environmental Medium. Amsterdam: Amsterdam University Press, 2019

DOI 10.5117/9789463729000_CHo4 


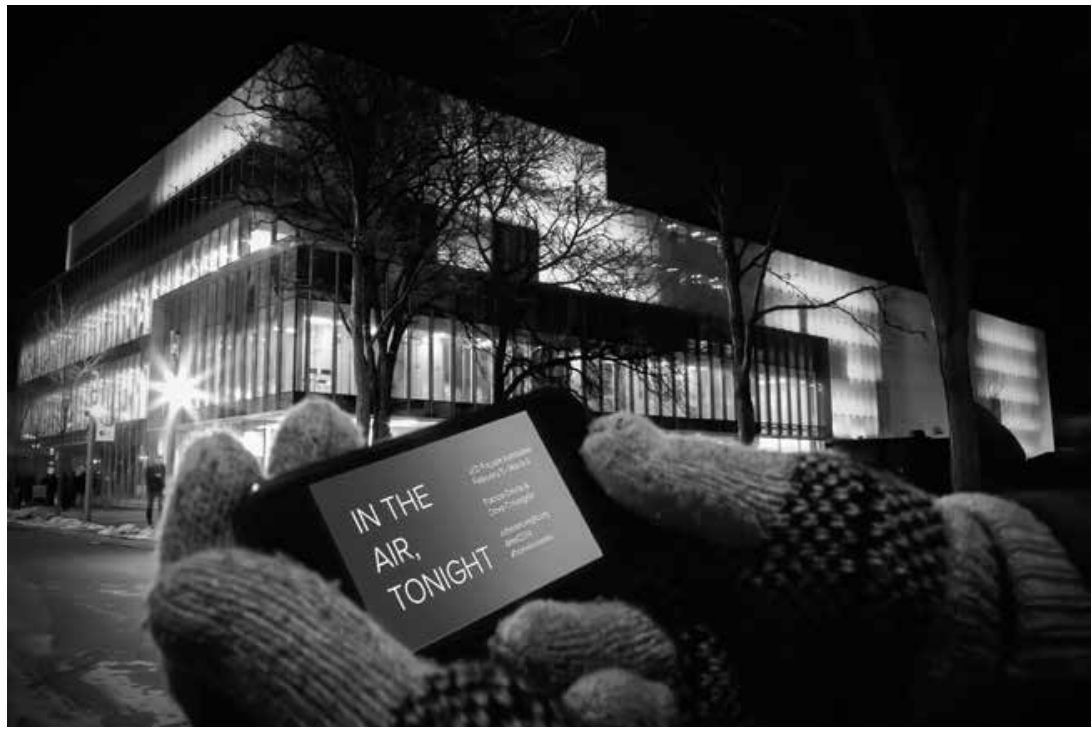

4.1: Public Visualization Studio, In the Air Tonight, Ryerson Image Arts Centre, Toronto, Canada 2014-2016. LED Media Façade, Website, Smartphones, Weather Sensors, Video, Twitter, Facebook. ๑ Public Visualization Studio.

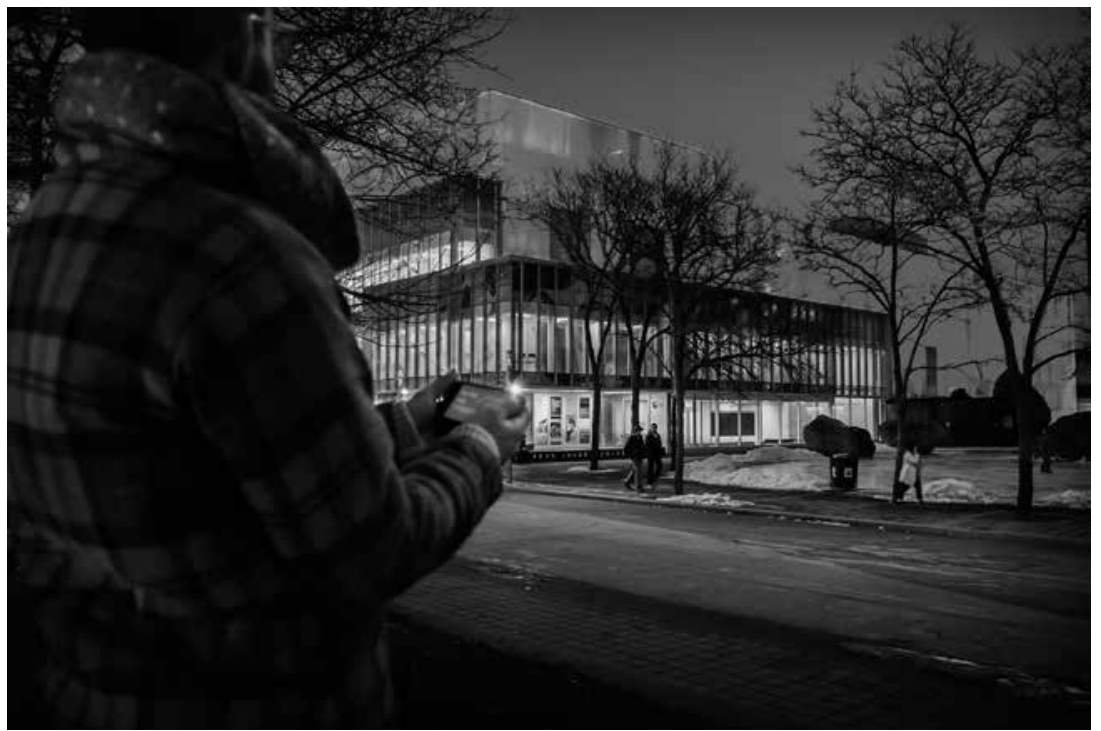

4.2: Public Visualization Studio, In the Air Tonight, Ryerson Image Arts Centre, Toronto, Canada 2014-2016. LED Media Façade, Website, Smartphones, Weather Sensors, Video, Twitter, Facebook. @ Public Visualization Studio. 
displayed fluctuating information about changing temperatures and wind speed. With the colour blue, it visualizes the feeling of being outside and exposed to the elements. This presents a translation from one sense (touch) to the other (sight). The data in between-from qualitative to quantitative and back - came from a weather station located on the roof of the building. Tweets that used the hashtag \#homelessness generated a red pulse on the building's surface. In response to financial donations, the façade intermittently turned white. A webcam enabled remote participants in the project to witness the building as it changed colours in real time. ${ }^{1}$

This work made use of the material architecture in which it was embedded to combine forms of remote sensing, individual interactivity, and public display. As such, the work aimed to raise public awareness for social concerns by visualizing and making present what is otherwise invisible-at the intersection of social and environmental problems specific to contemporary urban space. As an 'object to think with', this installation compels us to zoom out from the surface of screens to their situation.

In the Air Tonight embodies many of our contemporary fascinations: public spectacle, digital experimentation, and the affordances of new display technologies. And, like many other screen-based urban interfaces-from artistic screen installations and media façades to more mundane displays of information, advertisements, and commercial entertainment on the streets of our cities today-it also activates and updates characteristics of preceding screen paradigms. While addressing the present, such new assemblages invoke environmental aspects of panoramas, dioramas, and other visual spectacles from the past, especially from the eighteenth and nineteenth centuries. These historical spectacles created a mobile, pedestrian form of spectatorship that contributed to the rise of urban flânerie, which contemporary urban installations reference alongside optical illusions like the camera obscura, magic lanterns, and phantasmagorias. ${ }^{2}$

Recent public screen installations thus integrate visual technologies that recall early forms of urban lighting and display but infuse these with more activating, interactive possibilities. As environmental attractions, they bring back to the present a rich history of public performances and happenings at fairgrounds and other festivals and exhibitions. Moreover,

1 Drucker, p. 1. For more information about In the Air Tonight, see http://intheairtonight.org (accessed June 2017).

2 Although there is no end to the number of examples, the commitment to address social issues in their artistic form in other screen works is usefully discussed in the following studies. See Pop et al., 2017; McQuire, 2008. 
by working with light, colour, and movement for various optical effects, they examine and extend the city's material surfaces in line with a long tradition of ornaments and trompe l'oeil in architectural monuments such as cathedrals. As Joanna Drucker succinctly phrases it, 'Meaning is use, as Ludwig Wittgenstein famously said, to which we can add, such use is always circumstantial and situational'. And use is not a thing but an event that happens in the present. ${ }^{3}$

In this essay, I discuss In the Air Tonight and some other comparable installations, treating these works as vehicles that can guide us toward a more in-depth understanding of urban screens in general. Specifically, through a somewhat detailed consideration of a few such installations, I will focus on some of the ways in which these works use technologically enabled 'remote sensing' to address spectators as responsible subjects by putting them into new sensory relationships with their broader urban environment. These artworks stand for a wider variety of screen installations that infuse material architectural surfaces in our urban public spaces with matter — both in the sense of materiality and of social concern — by means of light and reflection, the latter in its double meaning of image and thought. These installations compel sensations: the activation of the senses that allow humans' bodies and minds to perceive and communicate with one another and with their material environment. Sensations are the events such artworks activate.

In the Western tradition, we distinguish five senses, some of which we assume require direct bodily contact (touch, taste) while others need only bodily tools (such as ears for hearing, noses for smelling, and eyes for vision) for experiencing at a distance. Vision is usually considered the most 'remote' of the senses, the one most capable of connecting over distances-even if there, too, sensing is based on the material contact of light. Today, we use the term 'remote sensing' to describe technology-driven productions of visual sensations at great distances. Yet this term in fact describes nothing more than an extension of what (human) vision has always been capable of

3 In The Lumière Galaxy, Francesco Casetti provides a perspective on the history of the cinema as one of changing assemblages. The cinematic assemblage is an 'alterable complex of components' and this concept allows us to recognize a dynamic field of technological changes and emerging practices. For a rich archaeology of the panoramic paradigm, see Huhtamo, 2013. About mobile spectatorship and immersion, see also Griffiths, 2002 and 2008. For an archaeology of urban screens as part of a longer history of what he calls 'public media displays', see Huhtamo, 2009. On the connection between contemporary urban screens and the historical, architectural ornament, see Caspary, 2009. About revisiting early travelling cinema, see Loipedinger, 2011. For a study of early cinema and the trope of travel and mobility, see Verhoeff, 2006. 
doing. Only the particular sensations produced, the experiences compelled, and the effects created by these two forms of 'remote sensing' differ from one another. Hence my claim that it is the situation, aided by technological affordances, that can make for a different kind of sensation that, being only 'remote' in appearance, is capable of encouraging engagement with our environment. With their display and interactive visualizations of remote sensing, the installations I discuss in this chapter align with Lev Manovich's statement that 'architects along with artists can take the next logical step to consider the "invisible" space of electronic data flows as substance rather than just as void-something that needs a structure, a politics, and a poetics'. That is, these artworks produce effects that the viewer can process as sensible material, according to my understanding of the relation between the senses and the sensations they produce. An important element of the specific works that I will discuss is that these sensations function in, and thus have an impact on, public space. ${ }^{4}$

To explore this paradoxical fusion of remote sensing and substance, I will consider how remote sensing shifts the screen's operations from surface to situation. In particular, I focus on works that visualize data generated from elsewhere. The screen projects under scrutiny here experiment with both optical and environmental qualities, as they provide visual interfaces to digital data that is either extracted from their direct environment - the spaces within which they are situated-or from more distant locations with which they are connected, by means of various sensing and display technologies. ${ }^{5}$ I will thus conceive of the screen's work as situated, architectural, and eventful.

In addition to In the Air Tonight, I will consider two other examples of the contemporary urban installation, both by Los Angeles-based artist Refik Anadol. Many of Anadol's installations interrogate the conventions of architectural screen-spaces. His Infinity Room and Virtual Depictions: San Francisco will be central to this essay. Anadol calls these works 'data sculptures', but in light of my own argument I propose the term 'screenarchitectures' to describe them. I choose this term in order to situate them alongside other examples of media architecture that work with screens or screen-like displays as well as more temporary and mobile screen-based installations that are—as screens always necessarily are—architectural. ${ }^{6}$

4 Manovich, 2006, p. 237.

5 On screen-based installations, see Mondloch.

6 Anne Friedberg makes the most convincing claim for this architectural perspective on the screen, in her landmark work, The Virtual Window (2006). 
These specific cases serve as my theoretical objects. That is, I look to specific artworks in order to explain the wider 'genre' of contemporary screen-architectures, a genre that I consider to be fundamentally site specific, or rather, site responsive. ${ }^{7}$ Screen-architectures enable and propose various forms of interface between an individual and his or her surroundings, whether those surroundings are immediate or more remote. These screenarchitectures not only display spectacular optical sights but also produce emergent environmental situations. This perspective on installations as screen-architectures expands on the concept of the dispositif to include the spatio-temporal assemblage of screening situations, an assemblage that includes the respective arrangement of spectator, screen, and image. ${ }^{8}$

Once we understand the dispositif as a fundamentally material and spatial arrangement, we can further analyze this arrangement as a spectatorial territory: it produces not only a spectator but also the territory within which spectatorship can occur. The particular screening situation of each spectatorial territory is layered and porous: each territory is permeable and opens up to other spaces. As we will see below, approaching the screen as part of a spectatorial territory can help us understand contemporary screen installation as historically connected to other mobile screening practices from the past, which entailed their own comparable and yet different spectatorial territories: the camera obscura, the magic lantern, and various forms of urban lighting being a few examples. These screening practices likewise shaped fields of vision for spectators who were positioned behind or in front of screens, or amidst the architectural façades that surrounded them. Within the spatial arrangements of these projection-based dispositifs, the image emerges as either transported from another realm, beyond the screen, or in continuity with the surrounding spectatorial space. However, the territorial aspects of spectatorship may not have been sufficiently analyzed to grasp the role of interactive digital urban interfaces in our contemporary moment. As I have argued elsewhere, mobile screens and

7 See Morra, 2017.

8 Hubert Damisch introduced the notion of theoretical objects, saying that such an object '[...] obliges you to do theory but also furnishes you with the means of doing it. Thus, if you agree to accept it on theoretical terms, it will produce effects around itself ... [and] forces us to ask ourselves what theory is. It is posed in theoretical terms; it produces theory; and it necessitates a reflection on theory'. (Bois et al., 1998, p. 8). As Mieke Bal has pointed out, his concept 'sometimes seems to suggest these are objects around which theories have been produced. At other times, [...] he attributes to the artwork the capacity to motivate, entice, and even compel thought'. (Bal, p. 8). In line with this latter capacity, I attribute to the works a theorization of their own status as elaboration of this genre of 'sensing screens'. 
location-based technologies have reorganized the dispositif in a variety of ways. ${ }^{9}$ Not only have they given screens a sense of physical mobility-of vehicular, portable, or wearable transportation - but they have also shifted the terms of interactivity and spectatorial agency. They make the spectator mobile in multiple senses of the word. But there is also a mobility implied in the variability of screens' operations, given that digital interfaces afford many different uses. Hence, mobile screen technologies reveal the dispositif to be fundamentally performative. Our processes of interfacing with screens within a dispositif and the ways we actively engage with those screens produce complex, changing, and interactive spaces. This process is a making of place that renders that place emergent; the place that hosts a site-specific screen is not pre-existing. Hence, the interfacing of viewer, screen, and dispositif is not only situated in the sense of taking place in a particular location. It also makes place as it creates or influences surrounding (urban) spaces. In this sense, it is also situating. ${ }^{10}$

\section{Site-responsivity: From translation to transformation}

In view of my brief description of this work at the beginning of the essay, let me now first address an interactive urban installation that, like many other works of screen-architecture, aims to raise awareness and solicit civic participation in urban social issues.

In the Air Tonight is an example of responsive architecture used for (realtime) data visualization that raises social awareness about urban issues (here: homelessness) by deploying — and reflecting on—sensing technologies. Under the surface, it is more complex than meets the eye, due to the way in which the interface translates a social issue (homelessness) into physical and experiential categories (feeling cold). It transfers something we can measure (temperature) and subsequently evaluate and display. Here, this display has a metaphorical visual form: a blue wave signifies 'coldness'. Yet it combines one data source (temperature) with other information (such as the number of tweets using the hashtag \#homelessness), thus drawing different registers of information from different locations and material contexts and symbolizing different indexical relationships between image and world. The installation makes a connection between very different

9 See Verhoeff, 2012.

10 Ibid. Erkki Huhtamo discerns vehicular, portable, and wearable mobile (screen) practices. See Huhtamo, 2015. 
spaces, making digital communication visual and hence sense-able. This particular form of interface makes perceptible the urban challenges we often take for granted, a transformation that attempts to change our attitude. As such, the installation aims to produce attentiveness and reflexivity and to compel viewers to action. The spectator is positioned as an insightful and conscientious citizen, aware of the presence and situation of others. This may stimulate donations, which might improve and transform the environment surrounding the installation itself."

Responding to its immediate environment - that is, its site of installation-this work demonstrates how data visualization not only communicates data from and about 'here' and 'there' but also allows an interface between these disparate spaces. It also represents the 'now' of the viewing subject in relation to this data as it extracts, translates, connects, and makes 'present' - both temporally and spatially_data about elsewhere in the 'now,' thus producing relations and, perhaps most pertinently, performing the act of sensing. The thrust of urban projects like In the Air Tonight is to activate local publics by stimulating reflection on their situation and transforming this reflection into social action. Sensing thus implies a distillation of information from the environment to which the perceiving subject becomes attuned - and is thus able to respond to the particulars of that environment. Sensing is not only subjective but also social; it can thus put the self and the senses in an ethical relation to others. ${ }^{12}$

Joanne Morra has proposed that we consider as 'site-responsive' any artwork that responds to its site of installation. An installation can act site-responsively when a work engages a space that is not primarily a site for exhibition. Morra writes that site-responsive interventions aim 'to render historical space contemporary, to critically engage with the museum, its collection, display strategies, narratives, and history, or to open the space up to a broader cultural context that includes artistic practice.' They can activate potential narratives, experiences, and meanings not otherwise obviously primary in the experience of a space. As a result of this activation, the work responds to the site and enables us to understand it differently from how we routinely perceive it. Because the viewer and the work interact, there is a clear reciprocity at play. 'Site-responsivity', Morra writes, 'acknowledges

11 See Verhoeff and Van Es, 2018. For a comparable installation that neatly resonates with the title of the present article, see Sensing Water by Seattle-based artist Dan Corson. For more about this work, see http://dancorson.com/sensing-water (accessed June 2017).

12 Urban screens and installations and their possible use for social awareness and civic participation are usefully discussed in Pop et al., 2017. About sensing technologies, smart technologies, and urban experiences, see Shepard, 2011. 
the way in which the artworks and space dynamically relate to, and respond to, one another'. ${ }^{13}$

This work in Toronto produces a new situation that moves very literally from the environmental to the optical, and which feeds back into the environment: environmental data about the climate affects a visual display, which in turn transforms its environment. I wish to underscore how this relation between the environmental and the optical is not a one-directional causal process but is complexly intertwined. Accordingly, I propose we understand these site-specific architectural and situated screens as siteresponsive urban interfaces. This change in terminology emphasizes how the screening situation not only takes place within a space that produces subjectivity but also produces a spectatorial territory that allows possibilities for action and transformation to emerge. While we perhaps tend to understand screen-based spectatorship first and foremost as based on attraction or immersion, we see here how site-responsivity combined with interactivity may yield situations that are performative: fundamentally emergent, dynamic, and transformative of the subject.

\section{Drowning in dimensions}

The following case may seem a bit exceptional—let's say, literally out of place-considering my focus on public screening situations. Contrary to exterior displays that cover the city's building façades, Refik Anadol's Infinity Rooms are closed interiors that fully immerse the spectator in an abstract spectacle of light and sound (figure 4.3). It is difficult to describe in words what we see in the rooms. Changing black-and-white light patterns (projected by lasers) surround the spectator. Mirrors cover the walls of the small space, visually effacing its boundaries. Engulfing sounds accompany the flow of light patterns. In this audio-visual spectacle, the visitor loses the visual boundaries and surfaces that typically serve as points of sensory reference. The projections of kaleidoscopic light patterns visually encompass the spectator and fill his or her entire field of vision, without the borders of a frame and without discernible walls, floor, and ceiling. As a consequence, the illusion of being both detached and then immersed is very powerful.

The work has appeared in various settings - for example, at the Istanbul Biennial (2015) and the SXSW festival in Austin, Texas (2017). Thus, the rooms 
travel and are (hence) site-adaptive - a form of site-specificity characteristic of many travelling installations that appear in different locations and for different publics, in each instance framed differently by the various occasions of their 'happening'. Another example would be the project Portals by Shared Studios, which in various locations places shipping containers that contain screen-based connections by means of live video links to other locations. Or, as the exhibition text by Shared Studios announced: 'Portals are gold spaces equipped with immersive audiovisual technology. When you enter a Portal, you come face-to-face with someone in a distant Portal, live and full-body, as if in the same room'. ${ }^{14}$

We can locate the historical roots of the Infinity Rooms - and by extension the Portals and other similar installations - in the intersecting optical and environmental aspects of these works. In particular, the early history of virtual reality would be an antecedent. As an immersive environment that travels to and is installed in various public spaces, it recalls early cinema exhibition, which often took place in fairgrounds, markets, circuses, and other travelling shows. It also recalls the mirrored rooms created by artists such as Lucas Samaras and Yayoi Kusama since the 1960s—rooms that used multiple facing mirrors to produce an effect of mise-en-abyme. These works are, in a sense, in line with the early nineteenth and twentieth-century practice of travelling exhibitions, which provided local spectators with a sort of virtual travel by showing both local and more exotic sights. Infinity Rooms, on the other hand, presents abstract visual forms based on programmed algorithms. Rather than visualize data from outside or elsewhere, the visual spaces are created in the 'here and now' by means of these algorithms that generate new, emergent environments. Compared to earlier practices, this shift from the transmission and representation of data to the construction of data space radically changes the spectator's optical and sensory experience. Anadol's immersive and box-like installations are perhaps more similar to early Virtual Reality, or the CAVES (Cave Automatic Virtual Environments) developed in the 1990s. The difference here, however, lies in the position of the subject. Rather than simply immersive-rather than entice people to drown in dimensions-Anadol's installation is interactive in the active sense. The spectator's awareness of his or her own body is not effaced but is instead foregrounded. ${ }^{15}$

14 See Shared Studios website, https://www.sharedstudios.com/ (accessed July 2018).

15 We can recognize a parallel with the Hales' Tours exhibition, even in the way the visual field is radically cut off from the outside, effacing the perspectival cues of horizon and scale, maximizing the optical effect of light and movement. For the connection between Hale's tours 


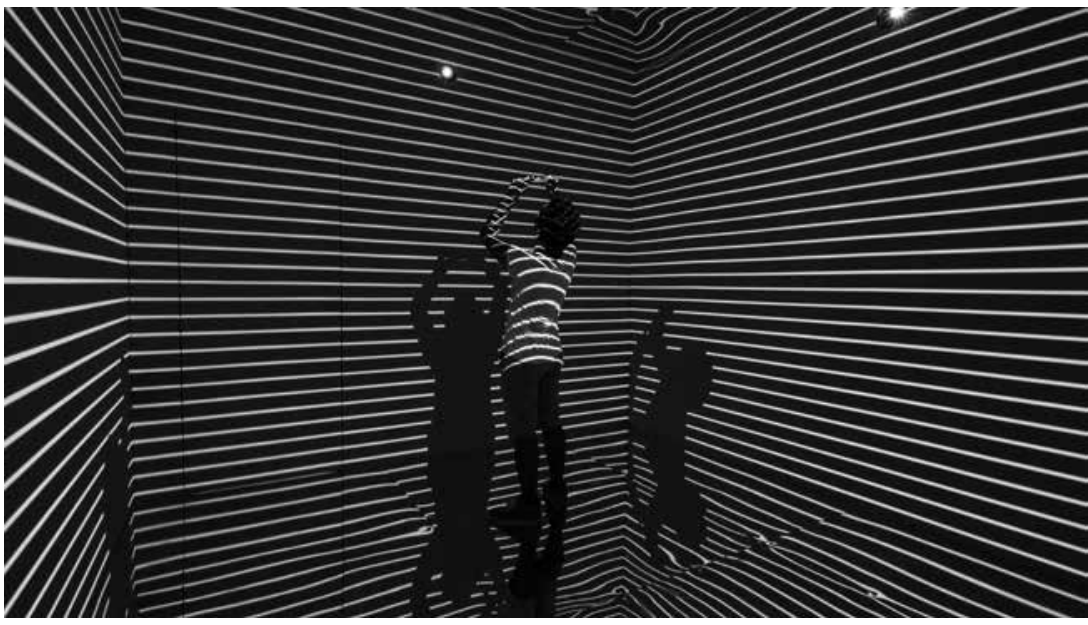

4.3: Refik Anadol (b.1985), Infinity Rooms, Instambul. 2015. Four channel Audio/Visual Installation running on custom software. ๑ Refik Anadol.

The work seems to be inspired by two trends that, put together, create a paradox. On the one hand, the artist suggests that the range and variety of screen technologies have caused us to become increasingly detached from our direct environment. This produces a sense of displacement. On the other hand, his artworks install a media architecture that makes explosive and innovative use of light and screen technology. Anadol thus proposes a temporary synthesis of the two poles of this paradox: between the displacing effects of media on the one hand, and their production of new, albeit temporary, spatialities on the other. His Infinity Rooms are part of an ongoing project that he calls 'Temporary Immersive Environment Experiments', intimating his attitude towards this paradox. Anadol understands the immersion produced by his Infinity Rooms as a 'state of consciousness where an immersant's awareness of physical self is transformed by being surrounded in an engrossing environment; often artificial, creating a perception of presence in a non-physical world'. ${ }^{16}$ What Anadol calls immersion needs

and modern ride films, see Rabinowitz, 1998. This historical connection also segues to a different track, connecting to the immersive environments of virtual reality; see Cruz-Neira et al., 1992. Interestingly, Anadol also experimented with VR versions of his Infinity Rooms but preferred the material, architectural version. In his words: 'We have so many opportunities in the physical world that we have never explored. [...] If you know this much better, then the leap to VR experiences will be much more meaningful, much more impactful.' See also Souppouris, 2017. 16 See Anadol's website at http://www.refikanadol.com/aboutrefikanadol (accessed June 2017) and http://www.refikanadol.com/works/infinity-room (accessed June 2017). On media 
a bit of elaboration. The artist creates the impression of boundlessness by taking away borders and surfaces. Immersion, here, is the result of the strategic production of a limitless visual space. The visitor's disembodied visual experience breaks with the dimensions of our common perception and experience of space. However, with these installations, Anadol aims at more than just disorientation:

In this project, 'infinity' is chosen as a concept, a radical effort to deconstruct the framework of this illusory space and transgress the normal boundaries of the viewing experience to set out to transform the conventional flat cinema projection screen into a three-dimensional kinetic and architectonic space of visualisation by using contemporary algorithms. ${ }^{17}$

The suggestion here is that the transgression of borders can create a disorientation that produces transformation. And that, of course, is the point. One might describe this as producing a different kind of spectatorial territory, an alternate scenography in which the screen becomes coterminous with every interior surface rather than serving as a singular focal point of attention, as in classical theories of the dispositif. ${ }^{18}$

The work's elimination of boundaries troubles the certainty of perspectival viewing inherent in the model of a single screen facing an audience. As Maaike Bleeker has written, perspectival projection 'creates a "scenographic space" in which all that is seen is in a sense staged for a viewer. At the same time, this staging aims at an effect that is quite the opposite of being theatrical: the promise presented by perspective is one of directness, immediacy, it is the promise of Alberti's finestra aperta. ${ }^{19} \mathrm{Or}$, as Anadol puts it, 'the experiment intends to question the relativity of perception and how it informs the apprehension of our surroundings'. ${ }^{20}$ Anadol's installations thus raise a question: can a different scenography for the screen be mobilized (that is, made mobile and also, literally, transformed) in more fundamental ways than its effacement? ${ }^{21}$

architecture, see Wiethoff and Hussmann, 2017.

17 See http://www.refikanadol.com/works/infinity-room (accessed June 2017).

18 It would be relevant, but take too much space, to involve dramaturgy as a critical concept, as it is discussed in Turners and Behrndt. For more about dramaturgy in relation to digital media, see Eckersall, Grehan, and Scheer. On scenography, see McKinney and Palmer, 2017.

19 Bleeker, 99 .

20 See http://refikanadol.com/works/infinity-room/ (accessed June 2017).

21 Surface is a cultural issue in many different fields. For an interdisciplinary take on surfaces, see Bruno, 2014. 


\section{Moving surfaces: Situating spectacle}

Another project by Anadol addresses this question: Virtual Depictions: San Francisco, a video wall created for the 350 Mission building. (Figures 4.4 and 4.5) Visible from the street but displayed on a surface lying behind a large glass façade, the work is literally situated both inside and outside of public space. It is a media wall: a screen surface that wraps around corners and which has the visual effect of a thick mass. Called a 'parametric data sculpture' by the artist, it is a work of screen-architecture; between screen surface and material, it is an architectural component.

Virtual Depictions fluidly displays changing abstract vistas-sometimes colourful, sometimes black-and-white-that, with special optical effects, visualize and animate otherwise static numeric, digital data from various sources. Though made visible and animated, this data is not 'legible' as such; there is no way to interpret or distil information from these spectacular and also enigmatic visuals. The images are abstract and are not accompanied by a legend, scale table, or other tools for interpretation. For example, the media wall might display information about the geographic origins of a series of tweets-but not in a map-like, readable image. Instead, the data sets are translated into a gripping visual spectacle. A trompe l'oeil effect enhances the kinetic and haptic appearance of the screen and its images, whose movement makes it seem as though the visual material protrudes from, and almost spills out of, its frame. This makes the screen, indeed, look more like a moving sculpture than a flat surface, even if it is actually the latter.

In his reflection on this work, Anadol invokes the installation's historical roots in the phantasmagoria and the cinematic screen. His media wall, in his words, 'turns into a spectacular public event making direct and phantasmagorical connections to its surroundings through simultaneous juxtapositions'. ${ }^{22}$ With this invocation of the phantasmagoria, the connection to pre-cinematic kinetic art and other forms of experimentation with visual movement brings a retrospective-or, as Mieke Bal would have it, a 'pre-posterous' - connection to historical moments and their meanings, yet to be disclosed. The work establishes an architectural hybridity. Its mobile surface expands and transforms its surroundings. It not only makes dynamic the appearance of the material structures but also suggests permeability

22 See http://www.refikanadol.com/works/virtual-depictions-san-francisco (accessed June 2017). Anadol's phrasing suggests he is purposefully alluding to the phantasmagorial tradition. About the legacy of the phantasmagoria and magic lantern in digital interfaces and media art, see Grau, 2010. 


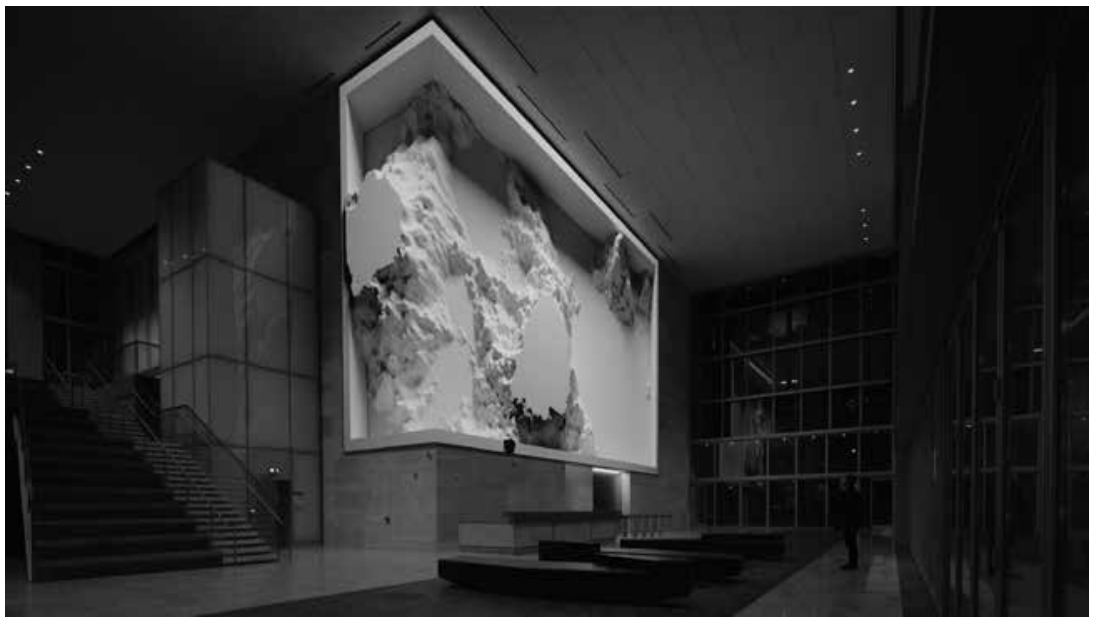

4.4: Refik Anadol (b.1985), Virtual Depictions, San Francisco. 2015. 6mm LED Media Wall. (c) Refik Anadol.

of its terrain. A crucial part of the work's situation is its positioning behind a glass façade; it thus displays a flowing spectacle of digital data layered under the reflected image of pedestrians passing by. As screen-architecture, this work expands and infuses its environment with optically vibrant visuals. Its visual suggestion of material fluidity brings life into the static surface of the façade. It speaks to our senses as we behold its movement. It is spectacularly beautiful, yet it firmly situates its spectacle in the everyday space that surrounds it. But does the spectacle also situate us? Or do we just look at it? ${ }^{23}$

\section{Mobilizing the senses}

The sensing and sensuous site-specificity of these works raises questions about their specific aesthetics. The three works discussed here are theoretical objects, illustrating the conceptual frameworks of remote-sensing, the spectatorial territory, and site-responsivity. All explore the relationship between the optical and the environmental - how the one infuses and intervenes in the other, and vice versa. The remote sensing technologies

23 On phantasmagoria as a tool for 'cultural optics', see Gunning. On the retrospective look at past art or 'pre-posterous' history, what has later been called 'anachronism' as a productive take on historical relations going in two directions, see Bal, 2010. 


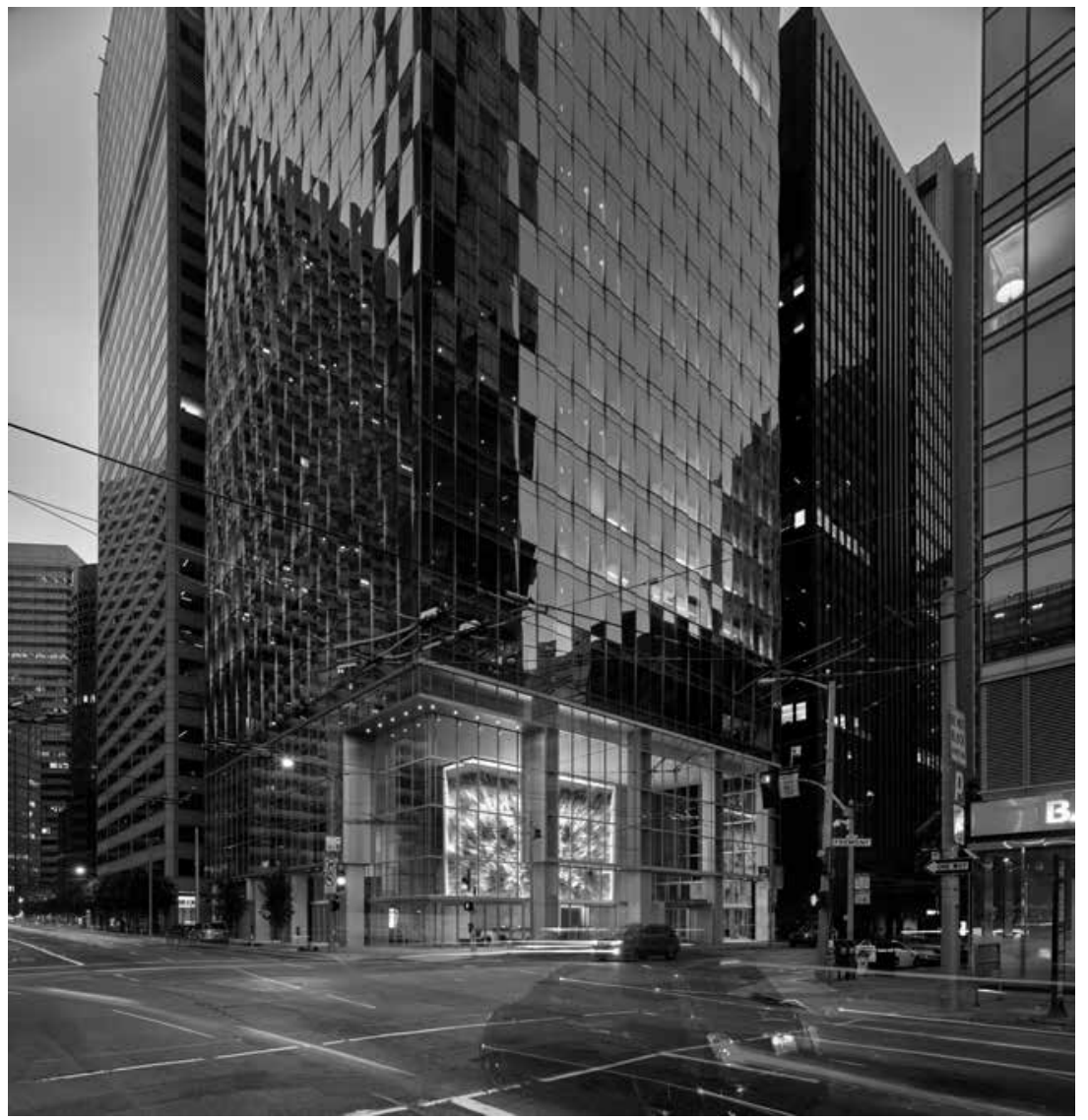

4.5: 350 Mission Street, San Francisco, a commissioned digital artwork animates a 70-by-38-foot LED screen that is visible from the street. @ Skidmore, Owings \& Merrill LLP | Cesar Rubio.

that enable these data visualizations reference, but do not require, the direct contact of bodily senses such as touch. How, then, ought we to understand the subject's own position and agency within this spatial screening situation?

I want to suggest that by screening, filtering, and territorializing, these works have a relationship of what we can call the 'curating' of the subject, in three different senses. First, the works design the space in which the subject is situated and construct or curate this space as emergent. Second, these works also curate data by filtering: selecting, processing, showing, and activating it. Third, as interfaces to this data, these works also curate a field of relations. Enclosing the subject with screens establishes a territory 
that is paradoxical: physically closed, yet apparently infinite. Screens in these works establish multiple pathways between a viewing subject and the data they display, so as to produce a dispositif through which subjects can constitute and transform themselves. This, then, is the emergent and relational situation that they produce: the territory of spectatorship's emergence. Hence my earlier claim that screen-architectures generate situations that can instigate specific kinds of sensations and that stimulate relational connections so as to infuse our environment with active, and actively curated, subjectivities. The kind of spectatorship at stake varies, however, depending on the specific screen-architecture at hand. In the Air Tonight aims to create a social consciousness in the spectator by linking specific stimuli to specific data, but Virtual Depictions: San Francisco does not. Instead, the latter work creates lush patterns and relief effects that do not allow viewers to recognize in familiar forms the data they depict.

What is at stake, then, when we consider the screen as a situation? This question, too, has a historical antecedent, which has recently resurfaced as an object of concern in media studies as well: the question of aesthetics. The mid-eighteenth-century philosopher Alexander Gottlieb Baumgarten is considered the founder of aesthetic theory. He described aesthetic experience as a mode of connecting, or binding, through the senses. And, since binding exceeds individual subjectivity, we can add: binding through the senses, in public space. Binding can connote sociality; the senses can be activated by encounters with artworks; and public space can be found in the urban environment. The works I have described in this essay offer exemplary intersections of these three aspects of aesthetic experience. All mobilize the senses. In the Air Tonight deploys colour to convey temperature. Anadol's Infinity Rooms amplify tactility and hearing in tandem while also enhancing but 'problematizing' vision through their disorientating effects. As such, the rooms simultaneously isolate and augment the visitor's senses. And Visual Depictions: San Francisco limits senses to vision, even when the work's haptic texture invokes the idea of touch. The work's animated materiality turns vision into more than itself. It makes vision tactile and hence binds viewers by mobilizing the desire to touch what they see and thus to come closer. ${ }^{24}$

24 As far as I know, and to my astonishment, Baumgarten's Äesthetik I has not been translated into English. Even the recently republished Encyclopedia of Aesthetics devotes a scant two pages to this work. For a relevant, politically oriented discussion of Baumgarten's aesthetics, see Gaygill, pp. 148-186. About the bond between aesthetics and practical life, as she calls it, Jill Bennett writes: '[Aesthetics] inclines not only toward the judgment of art [...] but also toward a more general theory of sensory-emotional experience, potentially crossing from the arts into psychology and social science.' Bennett, 2012, pp. 1-2. Earlier, Bennett recalled Baumgarten's 
Binding and public space, taking up the consequences of Baumgarten's view, operate in relation to each other. This is necessarily the case because binding not only happens through the senses but also between entities: between subjects and the objects they bind themselves to-such as, in this case, the installations. Binding is more than just enjoying. It is the transformation of the self under the influence and impact of an art object or sensory experience. In the cases I outline in this essay, the impact lies in how the works organize space, in the sensory appeal of screens and projections, and in the transformational appeal emanating from the experience of the work. This is where public space comes in: all three works use data visualization to truly impact the environment and thus augment the binding effect of the art object. More than just positioning the subject, binding invites the subject — or perhaps provokes the subject — to position him or herself in a bond with the environment. Situation, as I have used the concept here, implies that relations are not detached from the subjects; on the contrary, these works solicit subjects to participate in them, they persuade spectators to want to engage with them.

These installations, with their 'high-tech' look and feel, strongly evoke the idea of the contemporary: they project a sense of being in the now, and (with consideration of the spatial aspect) in the here-and-now. As such, they bring to fruition a latent aspect of older location-based cinematic screens: the capacity to bring the subject into direct relation with her environment. This type of screening is fundamentally and explicitly situational. However, more so than before, urban screen interfaces compel social engagements with the environments that surround them - including the city's problems, such as homelessness and social disconnection. Thus, the situation surrounding the screen becomes as 'animate' as the moving images projected upon it. Indifference in the face of these works is hard to sustain. Immanuel Kantstrongly influenced by, and yet polemical against, Baumgarten-proposed 'disinterestedness' as a condition for aesthetic experience. This has been much misunderstood as a form of indifference. But the detachment from self-interest, from the selfishness so rampant in contemporary capitalist culture, is also a necessary condition enabling individuals to reach out and engage - and to engage in the binding through the senses that Baumgarten proposed. We can say that these installations are exemplary acts of sensemaking: they bring a space, a subject, and data into sensitive connection.

conception of sensitive or sensuous knowledge: 'As a primary encounter, unconstrained by the categories, methods, and demarcations of other disciplines and practices, aesthetic perception is a unique nonscientific basis for inquiry.' Bennett, 2011, p. 119. 


\section{Works Cited}

Anadol, Refik. http://www.refikanadol.com/works (accessed June 2017).

Bal, Mieke. Of What One Cannot Speak: Doris Salcedo's Political Art. Chicago: University of Chicago Press, 2010.

——. Quoting Caravaggio: Contemporary Art, Preposterous History. Chicago: University of Chicago Press, 1999.

Baumgarten, Alexander Gottlieb. Äesthetik I (1750). Hamburg: Meiner Felix Verlag, 2007 .

Bennett, Jill. Practical Aesthetics: Events, Affects and Art after 9/11. London: I.B. Tauris, 2012.

Bleeker, Maaike. Visuality in the Theater: The Locus of Looking. London: Palgrave, 2008.

_- - 'Migratory Aesthetics: Art and Politics beyond Identity.' In Art and Visibility in Migratory Culture: Conflict, Resistance, and Agency, edited by Mieke Bal and Miguel Á. Hernández-Navarro, pp. 109-126. Amsterdam: Rodopi, 2011.

Bruno, Giuliana. Surface: Matters of Aesthetics, Materiality, and Media. Chicago: University of Chicago Press, 2014.

Casetti, Francesco. The Lumière Galaxy: Seven Key Words for the Cinema to Come. New York: Columbia University Press, 2015.

Caspary, Uta. 'Digital Media as Ornament in Contemporary Architecture Façades: Its Historical Dimension.' In Urban Screens Reader, edited by Scott McQuire, Meredith Martin, and Sabine Niederer, pp. 65-74. Amsterdam: Institute of Network Cultures, 2009.

Chateau, Dominique and José Moure, eds. Screens: From Materiality to Spectatorship -A Historical and Theoretical Reassessment. Amsterdam: Amsterdam University Press, 2016.

Corson, Dan. Sensing Water. See http://dancorson.com/sensing-water (accessed June 2017).

Cruz-Neira, Carolina, Daniel J. Sandin, Thomas A. DeFanti, Robert V. Kenyon, and John C. Hart. 'The CAVE: Audio Visual Experience Automatic Virtual Environment.' Communications of the ACM 35, no. 6 (June 1, 1992): 64-72.

Drucker, Johanna. 'Performative Materiality and Theoretical Approaches to Interface.' DHQ: Digital Humanities Quarterly 7, no. 1 (2013). Published at http:// www.digitalhumanities.org/dhq/vol/7/1/000143/ooo143.html.

Eckersall, Peter, Helena Grehan, and Edward Scheer, eds. New Media Dramaturgy: Performance, Media and New-Materialism. Basinstoke, UK: Palgrave, 2017.

Gaygill, Howard. Art ofJudgment, Oxford: Blackwell, 1989.

Grau, Oliver. 'Remember the Phantasmagoria! Illusion Politics of the Eighteenth Century and its Multimedial Afterlife.' In Media Art Histories, edited by Oliver Grau, pp. 137-161. Cambridge, MA: MIT Press, 2010. 
Griffiths, Alison. Shivers Down Your Spine: Cinema, Museums, and the Immersive View. New York: Columbia University Press, 2008.

- - Wondrous Difference: Cinema, Anthropology and Turn-of-the-Century Visual Culture. New York: Columbia University Press, 2002.

Gunning, Tom. 'Phantasmagoria and the Manufacturing of Illusions and Wonder: Towards a Cultural Optics of the Cinematic Apparatus.' In The Cinema: A New Technology for the Twentieth Century, edited by André Gaudreault, Catherine Russell, and Pierre Véronneau, pp. 31-44. Lausanne: Edition Payot, 2004.

Huhtamo, Erkki. Illusions in Motion: Media Archaeology of the Moving Panorama and Related Spectacles. Cambridge, MA: MIT Press, 2013.

_- . 'The Four Practices? Challenges for an Archaeology of the Screen.' In Screens: From Materiality to Spectatorship - A Historical and Theoretical Reassessment, edited by Domonique Chateau and José Mourre, pp. 116-124. Amsterdam: Amsterdam University Press, 2016.

_- _. 'Messages on the Wall: An Archaeology of Public Media Displays.' In Urban Screens Reader, edited by Scott McQuire, Meredith Martin, and Sabine Niederer, pp. $15^{-28}$.

In the Air Tonight. http://intheairtonight.org (accessed June 2017).

Loipedinger, Martin, ed. Early Cinema Today: The Art of Programming and Live Performance. KINtop Studies in Early Cinema. Frankfurt am Main and Basel: Stroemfeld Verlag, 2011.

Manovich, Lev. 'The Poetics of Augmented Space.' Visual Communication 5, no. 2 (June 2006): 219-240.

McKinney, Joslin and Scott Palmer, eds. Scenography Expanded: An Introduction to Contemporary Performance Design. London: Bloomsbury, 2017.

McQuire, Scott. The Media City: Media, Architecture and Urban Space. London: Sage, 2008.

McQuire, Scott, Meredith Martin, and Sabine Niederer, eds. Urban Screens Reader, INC Reader \#5. Amsterdam: Institute of Network Cultures, 2009.

Mondloch, Kate. Screens: Viewing Media Installation Art. Minneapolis: University of Minnesota Press, 2009.

Morra, Joanne. Inside the Freud Museums: History, Memory and Site-Responsive Art. London: I.B. Tauris, 2017.

Pop, Susa, Tanya Toft, Nerea Calvillo, and Mark Wright, eds. What Urban Media Art Can Do: Why, When, Where \& How. Stuttgart: avedition GmbH, 2017.

Rabinovitz, Lauren. 'From Hale's Tours to Star Tours: Virtual Voyages and the Delirium of the Hyper- Real.' Iris 25 (1998): 133-152.

Shared Studios website, https://www.sharedstudios.com/ (accessed July 2018). Shepard, Mark, ed. Sentient City: Ubiquitous Computing, Architecture, and the Future of Urban Space. Cambridge, MA: MIT Press, 2011. 
Souppouris, Aaron. 'Inside “Infinity Room”, A Dazzling SXSW Art Installation.' Endgadget 13 (March 2017), https://www.engadget.com/2017/03/13/ refik-anadol-infinity-room-video.

Turners, Cathy and Synne Behrndt, eds. Dramaturgy and Performance. Basinstoke, UK: Palgrave, 2016.

Verhoeff, Nanna. Mobile Screens: The Visual Regime of Navigation. MediaMatters. Amsterdam: Amsterdam University Press, 2012.

_- - The West in Early Cinema:After the Beginning. Film Culture in Transition. Amsterdam: Amsterdam University Press, 2006.

Verhoeff, Nanna and Karin van Es. 'Situated Installations for Urban Data Visualization: Interfacing the Archive-City.' In Visualizing the Street: New Practices of Documenting, Navigating and Imagining the City. Cities and Cultures, edited by Padram Dibazar and Judith Naeff, pp. 117-136. Amsterdam: Amsterdam University Press, 2018.

Wiethoff, Alexander and Heinrich Hussmann, eds. Media Architecture: Using Information and Media as Construction Material (Age of Access? Grundfragen der Informationsgesellschaft). Berlin: De Gruyter Mouton, 2017.

\section{About the Author}

Nanna Verhoeff is associate professor in the Department of Media and Culture at Utrecht University. Interested in comparative approaches to changing media forms, she investigates emerging and transforming media cultures from early cinema to contemporary mobile and location-based interactive screens and installations. Besides her work on $3 \mathrm{D}$ cinema and immersive screen media, she has published on mobile media, augmented reality, screen-based installations, and media architecture. Her books include The West in Early Cinema: After the Beginning (2006) and Mobile Screens: The Visual Regime of Navigation (2012). She is co-editor of a special issue on Urban Cartographies in Television and New Media (Spring 2017). In 2014, she initiated the interdisciplinary research group [urban interfaces] at Utrecht University - a platform for research on location-based and mobile media, art, and performance in urban public spaces. 